\title{
Safety Standards in Infant Nutrition: A United States Perspective
}

Dennis M. Bier

Baylor College of Medicine, Houston, Tex., USA

\section{Key Words}

Food safety · Children · GRAS - Federal food · Drug and

Cosmetic Act $\cdot$ Food Safety Modernization Act

\begin{abstract}
In the United States, the general standard for food safety is reasonable certainty of causing no harm under the intended conditions of use. In contrast to food safety policy in some other countries, the United States treats foods for infants and children no differently than foods for adults, other than requiring additional standards for infant formulas. In the United States, food safety falls under the regulatory control of more than a dozen government agencies. The principal responsibility is shared by the US Food and Drug Administration (FDA) and the US Department of Agriculture (USDA), but significant additional oversight authority is granted to the Environmental Protection Agency (EPA), the Centers for Disease Control and Prevention (CDC), and others. Furthermore, while a large number of legislative statutes provide the basis for regulatory oversight, the principal laws that govern food safety are the Federal Food, Drug and Cosmetic Act, the Federal Meat, Poultry Products and Egg Products Inspection Acts, and the Food Safety Modernization Act. The latter statute, enacted in 2011, has provided for a broad range of new
\end{abstract}

industry responsibilities for the safe manufacture of food products and has significantly expanded federal enforcement authority for violations. Copyright $\odot 2012$ S. Karger AG, Basel

\section{Introduction}

As has long been the case in the United States, food safety has been ensured by various federal laws and regulations. However, the situation is reasonably complex because oversight and enforcement authority is governed by more than 30 legislative statues [1]. Principal among these are the Federal Food, Drug and Cosmetic Act (FFDCA) [2], the Federal Meat, Poultry Products and Egg Products Inspection Acts [3-5], and the Food Safety Modernization Act (FSMA) [6]. Moreover, additional complexity is introduced by the fact that the authority to regulate food safety is shared by more than 15 federal agencies [1]. Thus, while the US Food and Drug Administration (FDA) has overall responsibility for foods, infant formulas, and dietary supplements, the US Department of Agriculture (USDA) has regulatory authority over meat and poultry products, and the Environmental Protection Agency (EPA) maintains oversight over pesticides and toxins that

\section{KARGER \\ Fax +4161306 1234 \\ E-Mail karger@karger.ch}

www.karger.com
(C) 2012 S. Karger AG, Basel

0250-6807/12/0603-0192\$38.00/0

Accessible online at:

www.karger.com/anm
Dennis M. Bier, MD

USDA/ARS Children's Nutrition Research Center

1100 Bates Street

Houston, TX 77030 (USA)

Tel. +1 713798 7022,E-Mail dbier@bcm.edu 
may contaminate food products [1]. But overlapping oversight authority affects a variety of foods. The FDA has authority over large commercial egg farms, but the USDA inspects plants that process eggs and egg products. The safety of allowable contaminants in the public water supply is the responsibility of the EPA, but the safety of bottled water is under the authority of the FDA. Likewise, the FDA has overall responsibility for the safety of seafood and fish products, including toxins and some chemical contaminants, while the EPA has additional, shared responsibility for other toxic contaminants such as methyl mercury. Dietary supplements are regulated by the FDA under a separate statute, the Dietary Supplement Health and Education Act [7].

\section{Foods for Infants and Young Children}

Nevertheless, irrespective of the federal agency responsible for regulatory oversight of individual foods or food products, the safety of foods fed to infants and children is, overall, treated no differently from foods fed to adults, since all must conform to the general safety standard that they must be safe (that is, provide reasonable certainty of doing no harm) under their intended conditions of use. Infant formulas are the one exception. Because commercial formula is often the sole source of nutrition for young infants, this food product category is subject not only to all the general regulations for food safety, but also to additional, specific, safety regulations codified within Section 412 of the FFDCA [8]. Among others, these include prescribed good manufacturing practices, regularly scheduled testing of nutrient content and microbiological quality (but not sterility), and requirements for record keeping and annual inspection. Furthermore, the regulations allow for product recall and testing should there be an indication that the formula does not meet nutrient standards, is adulterated or misbranded, or constitutes a human health risk for other reasons [8].

It is important to emphasize here that, while a large number of variables constitute the domain of infant formula safety, formula efficacy is determined by a single indicator, the ability to support normal infant growth. Moreover, additional attention should be drawn to the fact that US statutes and regulations do not single out for special consideration or rules so-called 'follow-on formulae' or 'processed cereal baby food and baby foods'. These foods, fed to infants and young children as weaning or complementary foods, are subject to specific food safety rules by the European Commission of the European Union [9].

Infant Nutrition in the USA

\section{Safety and Regulatory Aspects of Infant Formulas}

The US FDA does not approve infant formulas before they can be marketed. However, all formulas must meet the nutrient and other specifications outlined in the FFDCA Requirements for Infant Formulas [8]. Additional ingredients that are generally recognized as safe (GRAS) may be added as discussed in more detail below. The FDA does monitor formulas for safety and compliance with applicable regulations, including requirements for regular testing by the manufacturer, yearly inspections by the FDA, and mandatory recall if the FDA determines that an adulterated or misbranded formula presents a health risk [8].

In 2004, the Institute of Medicine of the National Academies of Science (US) issued a report entitled 'Infant Formula: Evaluating the Safety of New Ingredients' [10]. In the report, the committee recommended that 'potential benefits, along with safety, should be considered when adding a new ingredient to formulas' [10]. Adoption of this recommendation would constitute a new regulatory model that addresses the risk/benefit ratio rather than the current approach of simply addressing issues of safety. Moreover, while emphasizing the continued use of infant growth (measured as weight gain) as an indicator of safety, the committee recommended expanding the clinical evaluation to include more comprehensive end points including, among others, biochemical, organ function, and developmental-behavioral end points [10]. Furthermore, the committee recommended 'additional elements of a safety assessment' that included standardization of the elements of safety assessment, evaluating new ingredient bioavailability, tolerance, allergenicity, impact on intestinal microbiota, the effects of possible nutrient imbalances, industry implementation of an inmarket surveillance system based on the findings of preclinical and clinical studies, and industry establishment of qualified expert advisory panels in consultation with the FDA agency [10]. Because expert opinion is near the bottom of the established hierarchy for evidence-based assessment, the report may have benefited by an additional recommendation and process algorithm for formal systematic review of available evidence. The committee also reaffirmed that breastfeeding is the standard against which infant formulas should be tested. This recommendation leads to the conclusion that new infant formula ingredient(s) need to be tested against two controls, that is against human milk and against a version of the formula, presumably already approved for use, that does not contain the new ingredient(s) [10].

Ann Nutr Metab 2012;60:192-195 


\section{Food Safety Modernization Act}

In January 2011, the FSMA [6] became law in the USA. This statute provided the FDA with new authority to impose stricter controls over food production, processing and distribution. The FDA is now authorized to require that food manufacturers develop food safety plans that include hazard analysis and preventive controls. Additionally, among other provisions of the act, the FDA has authority to issue performance standards that prevent or eliminate significant food contaminants, to implement increased record keeping requirements that provide tighter food surveillance and 'trace back' through the supply chain, to mandate inspections and access plant records without notice, and to suspend plant operations for safety violations. Importantly, for the first time, the commissioner of the FDA is given authority to order mandatory product recall, if there is 'reasonable probability that an article of food ... is adulterated ... or misbranded ... and the use or exposure to such article will cause serious adverse health consequences or death to humans or animals' [6].

The reportable food registry provision of the FSMA has also provided the results of its first-year data collection on serious adverse health consequences [11]. The FDA received 2,240 submissions that met the FDA reporting requirements. Of the 229 that were industry primary reports, $37.6 \%$ were Salmonella reports, $14.4 \%$ were reports of Listeria monocytogenes, 2.6\% were reports of Escherichia coli O157:H7, and 34.9\% reflected reports of undeclared allergens or intolerances [11]. The bulk of the Salmonella contaminants were found in spices and seasonings, raw produce, animal feeds, and nuts and seeds [11].

\section{Additions to Foods}

In the United States, with one exception, all ingredients added to foods are considered either food additives or color additives and require a safety evaluation and premarket approval by the FDA [12]. The single exception applies to food additives only and deals with the addition of an ingredient that is GRAS for its intended use by qualified experts [12-14]. To be considered for GRAS status, manufacturers must supply the same information about the substance that is required for a formal FDA food additive application. However, it is important to emphasize here that the GRAS designation applies not to the ingredient alone, but to the intended specific use of the ingre- dient $[13,14]$. Thus, a substance may be GRAS for addition to some foods, but not GRAS for addition to others.

The safety standard applied to the determination of GRAS status is the same as the general safety principle applied to all foods, namely a reasonable certainty of no harm, and the evidence required to support safety is the same as that required for approval of any food additive [14]. Additionally, the evidence must be generally available, a condition usually interpreted to mean published in a peer-reviewed scientific journal, although this type of evidence may also be supported by unpublished data. Furthermore, the evidence must be generally accepted $[13,14]$. The latter condition is generally taken to mean (a) that the data have been published in the secondary scientific literature, such as scientific reviews or textbooks, (b) that the evidence has been used in recommendations of authoritative bodies such as the National Academies of Science, or (c) that the evidence is supported by the opinion of an expert panel that was specifically convened for the purpose of evaluating the evidence $[13,14]$. The last approach is commonly used.

One class of additives that do not readily lend themselves to GRAS affirmation is 'functional ingredients' since the intention of adding these ingredients is to affect a specific biological function. However, function (efficacy) is not a condition of GRAS affirmation, so the conventional GRAS approach is inadequate and inappropriate in such cases.

\section{Conclusion}

The legislative and regulatory approach to ensuring the safety of foods consumed by infants and children in the United States has evolved since the passage of the initial Pure Food and Drug Act more than a century ago, and the FFDCA that succeeded it 74 years ago. Although this evolutionary process has been accompanied by increased complexity, the regulatory system has adapted appropriately to the changing nature of food safety threats, both characteristics of biological evolution in general.

\section{Disclosure Statement}

The author is a member of the ConAgra Foods Scientific Advisory Board and is Chairman of the International Life Sciences Institute Research Foundation Board. He has consulted for various food and infant formula companies on an ad hoc basis, but holds no stock or other financial interests in any companies in the food industry. 


\section{References}

1 Longley R: The US Food Safety System. h t t p://usgovinfo.about.com/od/ consumerawareness/a/The-Us-Food-Safety-System.htm, 2011.

2 US Food and Drug Administration: Federal Food, Drug, and Cosmetic Act. http://www. fda.gov/regulatoryinformation/legislation/ federalfooddrugandcosmeticactfdcact/default.htm, 2011.

3 United States Department of Agriculture Food Safety and Inspection Service: Federal Meat Inspection Act. http://www.fsis.usda. gov/Regulations_\&_Policies/Federal_ Meat_Inspection_Act/index.asp, 2011.

4 United States Department of Agriculture Food Safety and Inspection Service: Egg Products Inspection Act. http://www.fsis. usda.gov/Regulations_\&_Policies/Egg_ Products_Inspection_Act/index.asp, 2011.

5 United States Department of Agriculture Food Safety and Inspection Service: Poultry Products Inspection Act. http://www.fsis. usda.gov/Regulations_\&_Policies/Poultry_ Products_Inspection_Act/index.asp, 2011.
6 United States Food and Drug Administration: Food Safety Modernization Act. http:// www.fda.gov/Food/FoodSafety/FSMA/ ucm 247548.htm, 2011.

7 United States Food and Drug Administration: Dietary Supplement Health and Education Act of 1994. http://www.fda.gov/RegulatoryInformation/Legislation/FederalFoodDrugandCosmeticActFDCAct/ Significant AmendmentstotheFDCAct/ ucm148003.htm, 2011.

8 United States Food and Drug Administration: Federal Food, Drug and Cosmetic Act Sec. 412. [21 USC \$350a] Requirements for Infant Formulas. http://www.fda.gov/RegulatoryInformation/Legislation/FederalFoodDrugandCosmeticActFDCAct/FDCActChapterIVFood/ucm107864.htm, 2011.
9 European Commission of the European Union: Foods for Infants and Children. http://ec.europa.eu/food/food/labellingnutrition/children/index_en.htm, 2011.

10 Institute of Medicine Committee on the Evaluation of Addition of Ingredients New to Infant Formula. http://www.nap.edu/openbook.php?isbn=0309091500, 2011.

11 United States Food and Drug Administration: Reportable Food Registry Annual Report January 2011. http://www.fda.gov/ Food/FoodSafety/FoodSafetyPrograms/ RFR/ucm200958.htm, 2011.

12 United States Food and Drug Administration: Determining the Regulatory Status of a Food Ingredient. http://www.fda.gov/Food/ FoodIngredientsPackaging/FoodAdditives/ ucm228269.htm, 2011

13 Heimbach JT: GRAS determination: a short course. Prepared Foods 2004;173:123-129.

14 US Food and Drug Administration: Generally Recognized as Safe (GRAS). http://www. fda.gov/Food/FoodIngredientsPackaging/ GenerallyRecognizedasSafeGRAS/default. htm, 2011. 